\title{
IR LASER PHOTOTHERMAL TRACE GAS DETECTION APPLIED TO ENVIRONMENTAL AND BIOLOGICAL PROBLEMS
}

\author{
H. S. M. de VRies, M. R. van Lieshout, F. J. M. Harren and J. Reuss \\ Department of Molecular and Laser Physics, University of Nijmegen, Toernooiveld, \\ 6525 ED Nijmegen, The Netherlands
}

(Received 30 May 1994)

\begin{abstract}
The photothermal effect is utilized for the detection of molecular trace gases in the open air, with high spatial and temporal resolution. An IR $\mathrm{CO}_{2}$ laser is used to excite specific molecules to higher vibrational levels. The subsequent change in temperature and refractive index is monitored by the deflection of a $\mathrm{HeNe}$ laser beam which crosses the $\mathrm{CO}_{2}$ laser beam. To improve the detection limit of the system the $\mathrm{CO}_{2}$ laser has an intracavity focus near to which the HeNe laser passes 31 times in a multipass mirror setup. A detection sensitivity of $1 \mathrm{ppbv}\left(\mathrm{C}_{2} \mathrm{H}_{4}\right)$ and $0.5 \mathrm{ppbv}\left(\mathrm{NH}_{3}\right)$ is achieved under practical conditions.
\end{abstract}

\section{INTRODUCTION}

To monitor molecular trace gases in the atmosphere the MIR wavelength region is very attractive. Many molecules of interest possess fundamental vibrational transitions in this region with large absorption strengths and which are not affected by predissociation or lifetime broadening as occurs often in the visible and UV spectral regions. Small molecules like $\mathrm{NH}_{3}, \mathrm{C}_{2} \mathrm{H}_{4}, \mathrm{H}_{2} \mathrm{O}, \mathrm{O}_{3}, \mathrm{CH}_{4}$, $\mathrm{C}_{2} \mathrm{H}_{6}$, etc. show clear fingerprint spectra which can be observed with e.g. $\mathrm{CO}_{2}$ and $\mathrm{CO}$ lasers. ${ }^{(1-5)}$ In practice these lasers have proven their reliability and have been implemented in trace gas detectors.

In this paper we present the photothermal deflection method as a fast and sensitive method to monitor trace gases in situ in the atmosphere. The photothermal deflection method is related to the photoacoustic effect. Molecular transitions are induced by laser radiation. At atmospheric pressure the excited molecules are de-excited by collisional relaxation. The photoacoustic effect utilizes the pressure wave coming from the heated region. Photoacoustics is very sensitive allowing detection of trace gases at and below one part per billion (ppbv, $1: 10^{9}$ ) level. ${ }^{(6)} \mathrm{A}$ serious drawback of photoacoustics can be the requirement of a closed flow system; due to sticking of molecules to the wall material memory effects can occur, which impede fast time responses. This problem is of particular importance for molecules with permanent dipole moments, like $\mathrm{NH}_{3}$. Use of the photothermal deflection technique is preferred for this type of molecule and also for reacting molecules (e.g. $\mathrm{O}_{3}$ ) for which sampling with a photoacoustic cell can show a systematic error in the measurement. The photothermal deflection (PTD) method is fast, local and permits surface-free measurements.

Attempts toward detection of ammonia employing $\mathrm{CO}_{2}$ laser based photoacoustic ${ }^{(7.8)}$ and (less sensitive) direct absorption detection systems ${ }^{(9)}$ lately received attention. Ammonia possesses high absorption coefficients and a clear fingerprint spectrum in the ${ }^{12} \mathrm{CO}_{2}$ and ${ }^{13} \mathrm{CO}_{2}$ laser wavelength regions. ${ }^{(1.10)}$ We have applied PTD to $\mathrm{NH}_{3}$. Ammonia and in liquid its counterpart, the ammonium ion, have a strong influence on the ecosystem. (11) Originating from emission sources (e.g. livestock wastes) $\mathrm{NH}_{3}$ contributes to soil acidification and disturbs the nutrient cycle. The dry deposition of ammonia in the Netherlands is responsible for $33 \%$ of soil acidification. ${ }^{(12)}$ 
The photothermal deflection technique not only allows contact-free measurements, but can also be used to determine trace gas concentrations locally. We applied this method to the biologically interesting problem of fruit ripening, particularly of tomatoes. In tomatoes a main gas exchange channel runs through the stem scar, where the berry was attached to the plant. Besides uptake of $\mathrm{O}_{2}$ and release of $\mathrm{CO}_{2}, \mathrm{C}_{2} \mathrm{H}_{4}$ is mainly emitted through this part. The production of this gaseous plant hormone increases during ripening of the tomato and its total production amounts up to $10 \mathrm{nl} / \mathrm{g} \cdot \mathrm{h}$.

\section{PHOTOTHERMAL DETECTION OF GASES}

The PTD method is based upon a change of refractive index caused by laser absorption of gas molecules. ${ }^{(13)}$ Due to non-radiative collisional decay the molecules redistribute their energy over the translational energy of neighboring molecules. A local increase in temperature, in the order of a few millidegrees, results. The refractive index of the air thus changes and a $\mathrm{HeNe}$ laser, which acts as a probe beam crossing above the heated region, is deflected.

Here, an IR $\mathrm{CO}_{2}$ laser is used to vibrationally excite the gas molecules. The $\mathrm{CO}_{2}$ waveguide laser is line tunable over 90 transitions between 9 and $11 \mu \mathrm{m}$ and has $100 \mathrm{~W}$ intracavity power at the strongest $\mathrm{CO}_{2}$ lines. The waveguide laser has an extended cavity (Fig. 1) with an intracavity waist of $280 \mu \mathrm{m}$, produced between an intracavity lens $(f=75 \mathrm{~mm})$ and the curved output mirror (radius of curvature $270 \mathrm{~mm}$, reflection of $98.5 \%){ }^{(14)}$ In this way a high local intensity is achieved producing a well-defined heated region where the probe laser passes over the pump beam. To
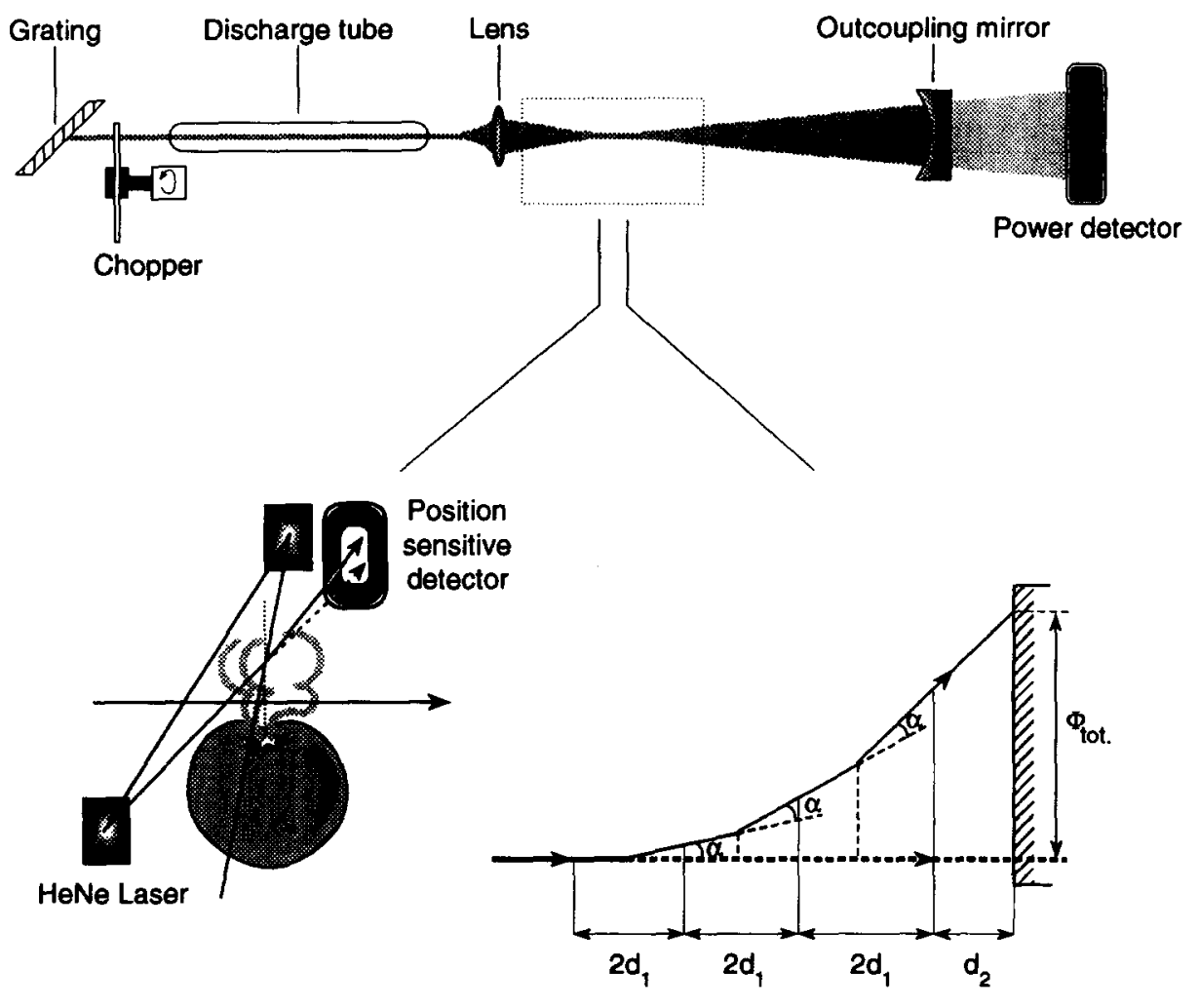

Fig. 1. Photothermal deflection setup. The $\mathrm{HeNe}$ laser beam passes over the intracavity $\mathrm{CO}_{2}$ laser waist at the maximum refractive index gradient (31 times) (a three pass arrangement is drawn here). Depending on the absorption strength of the trace gas molecules, each pass the HeNe laser beam is deflected over an angle $\alpha$, resulting in a total deflection $\Phi_{\text {tot }}, d_{1}$ is the distance between the mirrors, $d_{2}$ the distance from the second mirror to the position sensitive detector. 
improve the deflection signal the HeNe laser passes over the waist of the $\mathrm{CO}_{2}$ laser several times, by means of a multipass mirror system. Theoretically the total displacement $\Phi_{\text {tol }}=N^{2} d_{1} \alpha+N d_{2} \alpha$; with $2 d_{1}$ the distance between the two mirrors, $d_{2}$ the distance from the second mirror to the detector, $N$ the number of passes above the heated region and $\alpha$ the deflection angle per pass. Experimentally we are able to pass the $\mathrm{CO}_{2}$ laser waist 31 times which results in an improvement of the signal by a factor of 300 . Due to this multipass setup the probed dimension along the $\mathrm{CO}_{2}$ laser beam is $25 \mathrm{~mm} .{ }^{(15)}$ The deflection angle is proportional to the concentration of the absorbing gas. The $\mathrm{CO}_{2}$ laser is modulated at a frequency of $60 \mathrm{~Hz}$ by a mechanical chopper. The deflection of the probe laser is measured with a position sensitive quadrant detector, the output of which is fed into a lock-in amplifier.

The probe beam, its multipass system and the position sensitive detector are mounted on a rigid frame. This frame and the intracavity $\mathrm{CO}_{2}$ laser frame are rigidly coupled to suppress mechanical vibrations between the two laser beams. Air turbulence is diminished by shielding the laser beams, except for the detection region, and by utilizing a double probe laser beam. The HeNe laser beam is split into two equally intense, parallel beams passing the $\mathrm{CO}_{2}$ laser beam. One passes the pump laser near the intracavity focus at the optimum distance, where the refractive index gradient is maximum; the other passes the pump beam at a larger distance $(7 \mathrm{~mm})$ and is therefore not deflected. By subtracting both signals the influence of air turbulence is corrected for. ${ }^{(16)} \mathrm{All}^{\mathrm{NH}_{3}}$ measurements presented in this paper are performed with the double probe beam arrangement, while the $\mathrm{C}_{2} \mathrm{H}_{4}$ measurements are performed in a single probe beam setup.

Due to interfering absorption by other gases, e.g. $\mathrm{CO}_{2}$ and $\mathrm{H}_{2} \mathrm{O}$, switching between two laser lines is often necessary. The photothermal deflection measurements are performed in the laboratory at a constant temperature of $21^{\circ} \mathrm{C}$ and an ambient relative humidity. $\mathrm{CO}_{2}$ and $\mathrm{H}_{2} \mathrm{O}$ have ambient concentrations of $330 \mathrm{ppm}$ and $0.5-1.5 \%$ respectively. The $\mathrm{CO}_{2}$ absorption lines coincide exactly with the $\mathrm{CO}_{2}$ laser lines, resulting in a background signal equivalent to $25 \mathrm{ppbv} \mathrm{NH}_{3}$ at the $10 \mathrm{R} 8 \mathrm{CO}_{2}$ laserline. ${ }^{(1.17)} \mathrm{H}_{2} \mathrm{O}$ has a broadband dimer absorption in this wavelength region with a background value of about $2.5 \mathrm{ppbv} \mathrm{NH}_{3}$ at the $10 \mathrm{R} 8 \mathrm{CO}_{2}$ laser line.(18) Because of the barely structured absorption spectra variation in the concentrations of these gases results in an almost equal change of signal on both neighboring lines and the influence of $\mathrm{CO}_{2}$ and $\mathrm{H}_{2} \mathrm{O}$ is subtracted from the $\mathrm{NH}_{3}$-signal. During the experiment even small influences on neighboring lines are taken into account.

Including piezo optimization of laser power one measuring cycle is completed in $15 \mathrm{~s}$. For fast measurements within this time scale the $\mathrm{H}_{2} \mathrm{O}$ and $\mathrm{CO}_{2}$ concentration does not change drastically and measurements are performed at one laser line with the advantage that the response time amounts to only $0.1 \mathrm{~s}$.

\section{DETECTION OF AMMONIA}

The characteristics of PTD are compared to the results from a continuous flow denuder system under normal atmospheric conditions in open air. The denuder is a reliable, selective and sensitive ( 8 parts per trillion, $8: 10^{12}$ ) wet-chemical detection system. ${ }^{(19)}$ It is, however, rather slow with a response time of $60 \mathrm{~s}$. For eddy correlation experiments, a combination of wind speed, wind direction and concentration measurements, this response time is much too long, $0.5 \mathrm{~s}$ being required. ${ }^{(20)}$

In our laboratory ambient ammonia levels have been determined with PTD and the commercial wet-chemical denuder system around the clock during periods of $1 \mathrm{wk}$. During daytime the concentration was found to fluctuate slowly between 10 and 20 ppbv; during the night the average concentration decreases by $3 \mathrm{ppbv}$. Our detection limit amounts to $0.5 \mathrm{ppbv}$. In addition ammonium sources were prepared from 0.25 to $2.5 \%$ ammonia solutions in demineralized water to obtain ammonia concentrations of $10,30,60$ and $120 \mathrm{ppbv}$ in the sampling zone. The absolute 


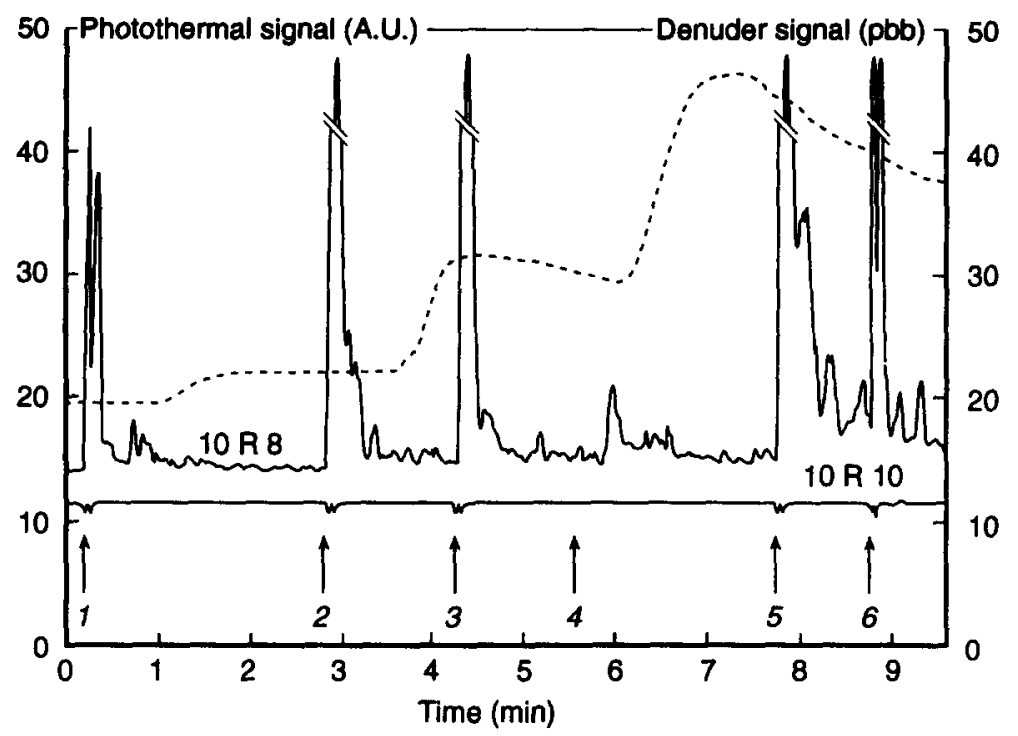

Fig. 2. Fast changes in $\mathrm{NH}_{3}$ concentration, by injecting ammonia-enriched air into the detection area six times. Injection No. 4 shows a delayed peak due to off-axis injection of the ammonia containing air. The denuder produces an integrated curve (-- ) due to its slow time response, while PTD monitors fast fluctuations on the ammonia absorbing $\mathrm{CO}_{2}$ laser line (10R8) and almost no change on the 10R10 reference line.

values for ammonia concentrations obtained from the denuder and PTD are in agreement within $15 \%$. For the denuder system the calibration is based upon liquid reference samples. For PTD the calibration is based upon comparative measurements with a certified $\mathrm{C}_{2} \mathrm{H}_{4}$ mixture in $\mathrm{N}_{2}$. The absorption strength of $\mathrm{NH}_{3}$ on the $10 \mathrm{R} 8\left(967.707 \mathrm{~cm}^{-1}\right)$ and $10 \mathrm{R} 10\left(969.140 \mathrm{~cm}^{-1}\right) \mathrm{CO}_{2}$ laser lines is taken into account ( 20.5 and $0.542 \mathrm{~cm}^{-1}$, respectively). ${ }^{(1)}$

Injections of air containing ammonia in the probe region were used to demonstrate the fast response time of PTD. The results are shown in Fig. 2; the arrows indicate the injection time of ammonia into the detection region. Due to its slow time response the denuder records an integrated curve (-- ), whereas the PTD setup (single line operation on the $10 \mathrm{R} 8 \mathrm{CO}_{2}$ laser line) reveals the ammonia passing in pulses through the detection zone. The signal is not disturbed by air turbulence as evidenced by the steady signal on the reference laser line. The photothermal deflection method yields ammonia concentrations in absolute and relative sense with a time response of $15 \mathrm{~s} \mathrm{(double}$ line operated) or $0.1 \mathrm{~s}$ (single line operated).

\section{LOCAL DETECTION OF ETHYLENE}

To demonstrate its spatial resolution PTD is applied to the local detection of ethylene emission by an intact cherry tomato. Ethylene is detected at two neighbouring laser lines, the 10P14 and $10 \mathrm{P} 12 \mathrm{CO}_{2}$ laser lines (949.479 and $951.192 \mathrm{~cm}^{-1}$, respectively). Compared to $\mathrm{NH}_{3}$ the collisional relaxation of the excited ro-vibrational level within the $\mathrm{C}_{2} \mathrm{H}_{4}$ molecule is slow, with an observable saturation at the high intracavity laser intensity in the probe region.

Due to this saturation the absorption coefficient of $\mathrm{C}_{2} \mathrm{H}_{4}$ at the $10 \mathrm{P} 14$ line is effectively decreased to $13.4 \mathrm{~atm}^{-1} \mathrm{~cm}^{-1}$ while the absorption coefficient at the $10 \mathrm{P} 12 \mathrm{CO}_{2}$ laser line is almost unaffected $\left(4.3 \mathrm{~atm}^{-1} \mathrm{~cm}^{-1}\right){ }^{(14)}$ To calibrate the system a reference cell was inserted at the crossing of pump and probe beams. The detection limit of the photothermal detection system is $1 \mathrm{ppbv}$ for ethylene in open air, which amounts to an equivalent sensitivity of $1.3 \times 10^{-8} \mathrm{~cm}^{-1}$. At this moment the sensitivity of the system is limited by interfering $\mathrm{H}_{2} \mathrm{O}$ and $\mathrm{CO}_{2}$ absorption. 


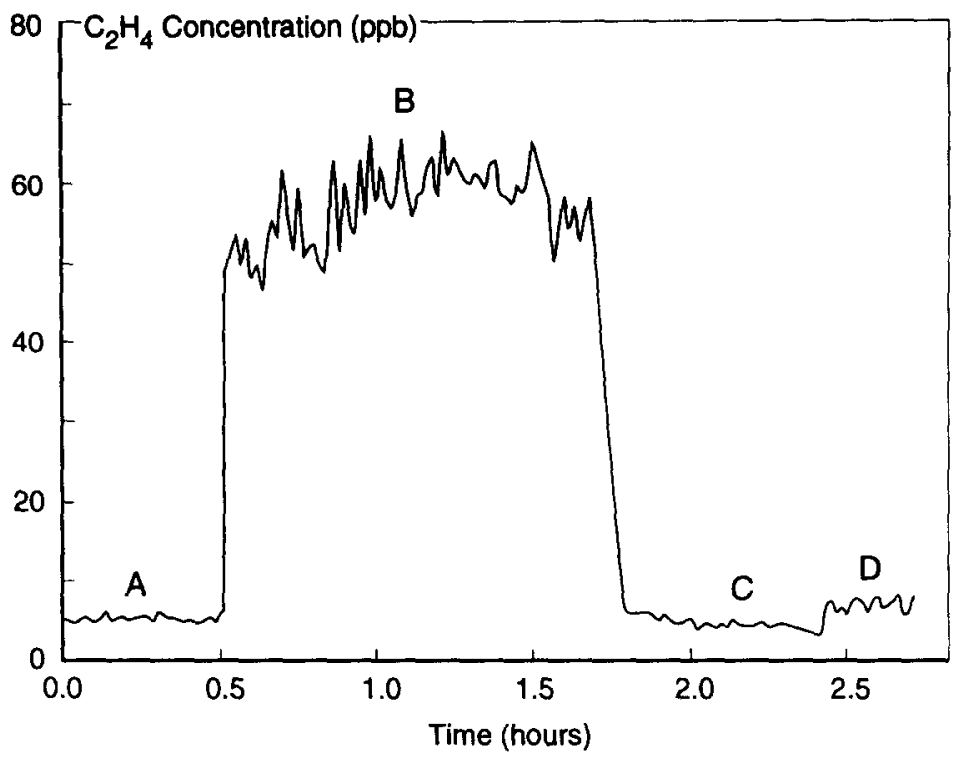

Fig. 3. A small cherry tomato is placed just below the crossing of the two laser beams. The results are shown for the $\mathrm{C}_{2} \mathrm{H}_{4}$ concentration in ambient air (A), above the stem scar of the tomato (B), at the bottom of the tomato $(C)$ and next to a wound caused by peeling off part of the skin (D).

The gaseous plant hormone ethylene plays an important role in developmental processes in plants. ${ }^{(21)}$ We applied our new technique to the specific case of tomato ripening, the role of ethylene in fruit ripening being well studied. ${ }^{(22,23)}$ During ripening tomatoes shows a strong increase in ethylene production coinciding with the climacteric rise in respiration $\left(\mathrm{CO}_{2}\right.$ production). Earlier in literature it was suggested that the main gas exchange channel (for e.g. $\mathrm{O}_{2}, \mathrm{CO}_{2}$ and $\mathrm{C}_{2} \mathrm{H}_{4}$ ) could be the stem scar of the tomato. However, in situ measurements of ethylene emission for undisturbed intact cherry tomatoes were lacking up to now.

To measure its ethylene emission, a small cherry tomato (Lycopersicon esculentum Cherry, dia $30 \mathrm{~mm}$, fresh weight $14 \mathrm{~g}$ ) is placed just below the crossing of the two laser beams. The distance

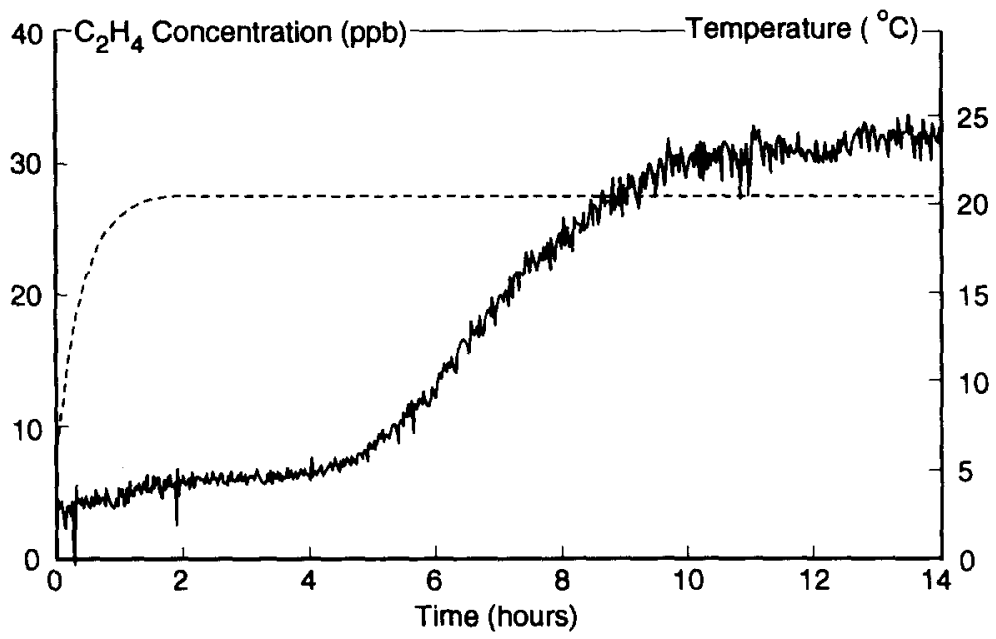

Fig. 4. The increase of ethylene production of a ripe cherry tomato being taken from the refrigerator $(5 \mathrm{C})$. measured above the stem-scar. The temperature (-- ) measured at the center of the tomato shows a warm up time of $c a 2 \mathrm{~h}$. The ethylene production, however, only slightly increases during that time, whereas an accelerating production occurs only after $5 \mathrm{~h}$ 
between the top of the tomato and the pump beam is approx. $1.5 \mathrm{~mm}$; a smaller distance heats up the surface of the tomato resulting in burning of the tomato skin. In Fig. 3 the results are shown for the $\mathrm{C}_{2} \mathrm{H}_{4}$ concentration in ambient air (A), above the stem scar (B), at the bottom of the tomato (C) and next to a wound caused by peeling off part of the skin (D). As can be seen from this figure the main exit channel for ethylene runs through the stem scar; the amount of ethylene emitted at the bottom site of the tomato yields a concentration just above the ambient level. Even if part of the skin is peeled off the local emission remains negligible. This suggests that the skin itself is not the main barrier for $\mathrm{C}_{2} \mathrm{H}_{4}$ diffusion. It can be assumed that ethylene produced in the central pulp of the tomato diffuses via the microchannels up to the stem scar rather than via the surrounding locular gel, with its high water content. The diffusivity of $\mathrm{C}_{2} \mathrm{H}_{4}$ through water is four orders of magnitude lower as compared to air.

Figure 4 shows the increase of the ethylene production of a ripe cherry tomato being taken from the refrigerator $\left(5^{\circ} \mathrm{C}\right)$, together with the increase in temperature at the center of the tomato. Within $2 \mathrm{~h}$ the tomato is warmed up to room temperature. The ethylene production measured above the stem-scar slightly increases during that time, whereas an accelerating production occurs only after $5 \mathrm{~h}$. This experiment demonstrates the long-term stability of the detection; the increase in "noise" level at higher concentrations $(8-14 \mathrm{~h})$ can be attributed to irregular gas emission from the stem scar.

Acknowledgements - This work has been supported by the European Union (Science program) and the national Dutch Technology Foundation (STW). We also like to thank G. P. Wijers and J. Slanina (ECN, Petten) for making available the chemical denuder system.

\section{REFERENCES}

1. R. J. Brewer and C. W. Bruce, Appl. Optics 17, 3746 (1978).

2. R. J. Brewer, C. W. Bruce and J. L. Mater, Appl. Optics 21, 4092 (1982).

3. S. Bernegger and M. W. Sigrist, Infrared Phys. Technol. 30, 375 (1990).

4. P. L. Meyer and M. W. Sigrist, Rev. Sci. Instr. 61, 1779 (1990).

5. F. G. C. Bijnen, F. J. M. Harren, J. Reuss, A. H. A. M. van Hoek, T. A. van Alen and J. H. P. Hackstein, Lasers in Remote Sensing. Springer Verlag, Heidelberg (1994). In press.

6. F. J. M. Harren, J. Reuss, E. J. Woltering and D. D. Bicanic, Appl. Spectrosc. 44, 1360 (1990).

7. A. Olafsson, M. Hammerich, J. Bülow and J. Henningsen, Appl. Phys. B 49, 91 (1989).

8. R. A. Rooth, A. J. L. Verhage and L. W. Wouters, Appl. Optics 29, 3643 (1990).

9. W. Meienburg, H. Neckel and J. Wolfrum, Appl. Phys. B 51, 94 (1990).

10. Z. Zelinger, I. Jancik and P. Engst, Appl. Opt. 31, 6974 (1992).

11. J. W. Erisman, Ph.D. Thesis. University of Utrecht, The Netherlands (1992).

12. G. J. Heij and T. Schneider, Report 200-09. Dutch priority programme on acidification, Bilthoven, The Netherlands (1991).

13. W. B. Jackson, N. M. Amer, A. C. Boccara and D. Fournier, Appl. Opt. 20, 1333 (1981).

14. F. Harren, F. Bijnen, J. Reuss, L. A. C. J. Voesenek and C. W. P. M. Blom, Appl. Phys. B 50, 137 (1990).

15. H. S. M. de Vries, F. J. M. Harren and J. Reuss, Springer Series in Optical Science, Vol. 6S, p. 12. Springer Verlag, Heidelberg (1992).

16. H. S. M. de Vries, F. J. M. Harren, M. P. A. van Opbergen and J. Reuss, Air Pollution Research Report, Vol. 47, 97. E. Guyot SA, Brussels (1993).

17. L. S. Rothman, R. R. Gamache, A. Goldman, L. R. Brown, R. A. Toth, H. M. Pickett, R. L. Poynter, J.-M. Flaud, C. Camy-Peyret, A. Barbe, N. Husson, C. P. Rinsland and A. H. Smith, Appl. Optics 26, 4058 (1987).

18. G. L. Loper, M. A. O'Neal and J. A. Gelbwachs, Appl. Optics 22, 3701 (1983).

19. G. P. Wijers, R. P. Otjes and J. Slanina, Atmos. Environ. (1994). In press.

20. D. W. Stocker, D. H. Stedman, K. F. Zeller, W. J. Massman and D. G. Fox, J. Geophys. Res. 98,12619 (1993).

21. S. F. Yang and N. E. Hoffman, Ann. Rev. Plant Physiol. 35, 155 (1984).

22. F. B. Abeles, P. A. Morgan and M. E. Salveit Jr, Ethylene in Plant Biology. Academic Press, New York (1992).

23. J. B. Biale and R. E. Young, Recent Advances in the Biochemistry of Fruit and Vegetables. Academic Press, London (1981). 